\title{
The Trail Making Test in Morocco: Normative Data Stratified by Age and Level of Education
}

\author{
Asmaa Oumellal1,2, Mustapha El Alaoui Faris ${ }^{1,2}$, Maria Benabdeljlil1,2 \\ ${ }^{1}$ Service of Neurology A and Neuropsychology, Specialty Hospital, Rabat, Morocco \\ ${ }^{2}$ Faculty of Medicine and Pharmacy, University of Research: University Mohammed V, Rabat. Morocco \\ Email: oumellal.asmaa@gmail.com
}

How to cite this paper: Oumellal, A., Faris, M. El A. and Benabdeljlil, M. (2018) The Trail Making Test in Morocco: Normative Data Stratified by Age and Level of Education. Open Journal of Medical Psychology, 7, 1-12.

https://doi.org/10.4236/ojmp.2018.71001

Received: November 3, 2017

Accepted: December 25, 2017

Published: December 28, 2017

Copyright $\odot 2018$ by authors and Scientific Research Publishing Inc. This work is licensed under the Creative Commons Attribution International License (CC BY 4.0).

http://creativecommons.org/licenses/by/4.0/

\begin{abstract}
The purpose of this study is to design a Moroccan Trail Making Test B; explore the effects of age, education and gender on the performance of the Trail Making Test (TMT); and provide normative information in Moroccan subjects. Our normalization study was conducted on 348 subjects (156 female and 192 male). The subjects were classified into four groups based on age (18 - 39 years, 40 - 59 years, 60 - 69 years and $\geq 70$ years), and three groups based on educational level ( 3 - 6 years, $7-10$ years and $\geq 11$ years). The data were analyzed using descriptive statistics through SPSS. The results displayed that increasing age and decreasing levels of education significantly result in a decreased performance on the Trail A, Moroccan Trail B and English Trail B. Only 229 bilingual subjects among the 348 initial subjects completed both versions of Trail $B$. There was no significant difference on performance between Moroccan Trail B and English Trail B for these subjects.
\end{abstract}

\section{Keywords}

Trail Making Test in Morocco, Cross-Cultural Neuropsychology, Normative Data

\section{Introduction}

\subsection{Description of the Trail Making Test}

The original form of Trail Making Test was named The Taylor Number Series. Later, Partington revised it in 1938, and renamed it as Test of Distributed Attention [1]. Prepared and renamed by psychologists in the United States Army in 1944, Trail Making Test was part of the Army Individual Test of General Ability. Subsequently it was incorporated into the Halstead-Reitan Battery [2]. 
The Trail Making Tests are very simple ones, and they are among the most commonly used neuropsychological tests in clinical practice [3]. They provide information on attention, visual search and scanning, sequencing and shifting, psychomotor speed, abstraction, flexibility, ability to execute and modify a plan of action, and ability to maintain two trains of thought simultaneously [2] [4] [5].

The TMT consists of two parts: TMT-A and TMT-B. The part A consists of one sample test and one task. Subjects have to connect the numerated circles from 1 to 25 , which are randomly spread over a sheet of paper, in an ascending order (as 1-2-3-4-...) as quickly as they can. The time taken to join consecutive numbers is the score, as it reflects the visual search ability and motor skills. Part $B$ consists of a sample test as well as the main task. Subjects are asked to combine randomly spread numbers (from 1 to 13 ) and letters (from A to L) with straight (direct) lines. The subjects must provide correct alignment of both numbers and letters in an ascending order, as one number and one letter (1-A-2-B-3-C-...) as fast as they can. The score is only based on the time taken which reflects the ability for cognitive alternation. In case of an error the examiner corrected it immediately, and the subject proceeded from the point where the mistake occurred (at the expense of additional time).

\subsection{Other Versions of the Trail Making Test}

Different forms were developed from The TMT test, like Comprehensive Trail Making Test [2], The Symbol Trail Making Test [6], The Clock Trail-Making Test [7], Color Trails Test [8], and The Expanded Trail Making Test [9].

Various versions of the TMT are also available. They were adapted to different cultures and languages: Arabic [10] [11], Chinese [12], Hebrew [13], Japanese [14], Italian [15], Indian [16].

\subsection{Neuroanatomical Correlates}

The results from the Functional Magnetic Resonance Imaging (fMRI) Study identify significantly greater activation during the TMT in right inferior/middle frontal cortices, right precentral gyrus, and left angular gyrus/left middle temporal gyrus [17]. These are the regions that most likely underlie cognitive flexibility during the TMT and are candidate regions underlying the impairment of groups with poor set-shifting abilities. These results are consistent with those presented in these studies [18] [19] [20].

\subsection{Sensitivity to Neurocognitive Deficits}

Trail Making Tests are sensitive to progressive cognitive decline in brain damage, schizophrenia, dementia and learning disorders [2] [21] [22]. Performances on Trails A and B decline with advancing age (with greater variability between individuals with increasing age), and lower levels of educational achievement [2]. Cultural/linguistic variables may affect test scores [23] [24] [25] [26]. 


\subsection{Language Situation in Morocco}

Morocco is characterized by language and cultural complexity. Moroccan society has had a long tradition of multilinguism and multiculturalism. This became more prominent since the beginning of the twentieth century as a consequence of colonization and international processes, most notably globalization [27]. In 1912, the French language was introduced by the French protectorate as the principal language of literacy for most educated Moroccans. This is the case whether a student comes from a Moroccan Arabic-speaking or Amazigh-speaking milieu. Since 1987, in public schools, French is learned as a second or third language and a second literacy after Arabic when children enter the second grade of primary school. English is studied as a third language when a student enters the ninth grade of secondary school. In private schools French and English are usually introduced during earlier stages of childhood, and sometimes before introducing the Arabic language.

In Morocco English enters into competition with French. Enrollments in English language programs have been growing exponentially over the past five to ten years. Although the Moroccan Government has announced its desire (in 2015) to replace French with English as the primary language of higher education, it has yet to take the necessary steps. This fact is shared among some North African countries, namely Algeria and Tunisia [28].

This situation of language complexity influences Moroccan neuropsychologists, both clinicians and researchers, about which language to use to examine the performance of Moroccans, on currently available neuropsychological tests. Unfortunately, for educated Moroccan subjects, most neuropsychological tests and their norms are thus applicable to most cultural groups in the western country. Adapting tests is necessary for linguistic and sociocultural differences.

\subsection{Objective of the Study}

The purpose of the study is to provide the initial normative information of Moroccan version of the TMT for educated Moroccan subjects; to examine the influence of age, gender and education level on the time necessary to complete the test; and to use our normative information on the TMT for cross-cultural comparisons of the TMT performance.

\section{Methods}

\subsection{Ethics}

All subjects were informed about the objectives and procedures involved in the study, and provided oral informed consent prior to the interviews and tests.

\subsection{Subjects}

This study was conducted between October 2011 and February 2012, it involved 348 healthy volunteers from undergraduate university classes, university staff, social organizations and a pool of people employed in or retired from govern- 
mental and/or private institutions, ranged in age from 18 to 85 years $(\mathrm{M}=51.57$ $\pm 18.32)$. The education level varied from 3 to 26 years $(M=9.21 \pm 4)$. The male to female ratio was (192 to 156). All persons scored higher than $23(\mathrm{M}=27.57 \pm$ 2) on the Mini Mental State Examination (MMSE; Folstein, Folstein, \& McHugh, 1975).

A self-reported history of medical and psychiatric problems was obtained from each participant. Patients with a medical history of neurological disease, psychiatric illness, or any other difficulty that may interfere with testing were excluded from the study. Individuals with minor physical abnormalities (e.g. diabetes with no serious complications, essential hypertension, etc.) were included. For Trail A people who could not read or could not recall the sequence of Arabic numerals were excluded. For Trail B people who could not understand the test instructions, could not read or could not recall the sequence of the Arabic or Latin alphabet were excluded. Moroccan version of the Mini Mental State Examination (MMSE; Folstein, Folstein, \& McHugh, 1975) was used with all participants to confirm that they are cognitively healthy adults. There was no time limitation for the TMT.

\subsection{Test Procedure}

The Moroccan version of the MMSE [29], the Trail Making Test-A, English Trail B and Moroccan Trail B, were administered by two trained clinical neuropsychologists. The TMT was conducted according to the standard administration procedure described by [2].

In the Moroccan version of Trail B (see Figure 1), the Arabic numerals were used $(1,2,3)$ in contrast to Hindi numerals used by [10] [11]. In Morocco the population only uses Arabic numerals. In our testing Arabic letters ( $I_{-}+$) were used to replace the respective Latin letters of the English TMT (A B C...).

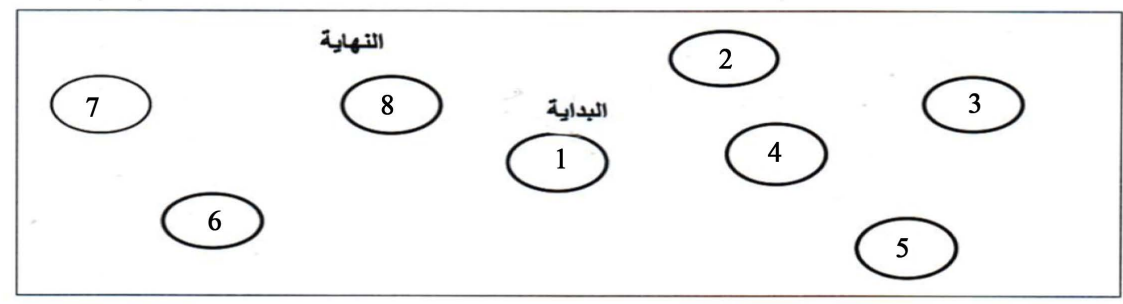

Example A

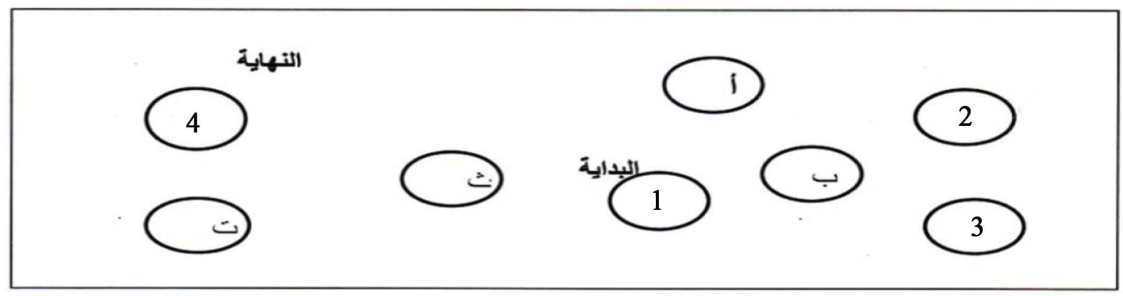

Example B

Figure 1. Sample items for forms A and Moroccan Trail B. 
The words "Begin" and "End" were translated into Arabic for the Moroccan Trail B, and into French for the English TMT (as in French Canadian TMT). Instructions are given in Moroccan Arabic and French (depending on the subjects).

Before each part of the test, a practice trial was administered to make sure the individuals understood each task. The time to complete each part of the TMT was recorded, which represented the TMT-A and TMT-B scores (in both versions). If the subject made mistakes, the examiner corrected it immediately. Errors were also counted, but were not considered an indication of the performance level of the subject.

\subsection{Statistics}

The data was analyzed using SPSS 13.0, separated into the Kruskal-Wallis Test and chi-square $\left(\chi^{2}\right)$. These were performed to examine the relative effect of age and education on each test score. Multiple comparisons by the post hoc tests were used to identify significant differences on TMT performance between the three groups of educational level. In addition the Mann-Whitney Test was performed to assess the effect of gender. A significance level of 0.05 was set for all means contrasts.

The mean score in the MMSE of all subjects was $27.57 \pm 2$. TMT was administered to 348 Moroccan subjects. All 348 completed Trail A. Moroccan Trail B was completed by 308 individuals. English Trail B was completed by 262 individuals; the others could not understand the test instructions or were unable to recall the sequence of the alphabet correctly.

Ultimately only 229 bilingual subjects of the initial 348 subjects completed both versions of Trail B. The 229 subjects include all ages, both genders and all levels of education.

The mean score in Moroccan Trail-B was $129.63 \pm 48.56$; and in the English Trail-B $129.43 \pm 48.76$. There was no difference in performance observed between the two means.

\subsubsection{Analysis 1: Gender Effect}

Statistical analysis shows that performance on the TMT was not affected by gender; Trail-A $((\mathrm{Z})=-0.78, \mathrm{p}=0.43)$; Moroccan Trail $\mathrm{B}((\mathrm{Z})=-0.03, \mathrm{p}=$ $0.96)$; English Trail $B((Z)=-0.89, p=0.36)$.

\subsubsection{Analysis 2: Aging Effect}

The subjects were classified into four groups according to age: 18 - 39 years $(M=$ 26.81), 40 - 59 years $(M=4.99), 60-69$ years $(M=63.692)$ and $\geq 70$ years $(M=$ 74.6), respectively. Statistical analysis of the three scores of the TMT showed that they were significantly affected by age Trail A: $\left(\left(\chi^{2}\right)=99.033, \mathrm{p}=0.000\right)$; Moroccan Trail B: $\left(\left(\chi^{2}\right)=20.249, \mathrm{p}=0.000\right)$; English Trail B: $\left(\left(\chi^{2}\right)=16.787, \mathrm{p}=\right.$ $0.00)$. Increasing age hence is highly associated with decreased performance on the TMT. 


\subsubsection{Analysis 3: Educational Effect}

The subjects were classified into three groups according to educational level: 3 6 years $(M=5), 7-10$ years $(M=8.97)$ and $\geq 11$ years $(M=13.87)$, respectively. The scores of TMT were affected by educational level: Trail A $\left(\left(\chi^{2}\right)=56.32, p=\right.$ $0.000)$; Moroccan Trail B: $\left(\left(\chi^{2}\right)=30.62, p=0.000\right)$; English Trail B $\left(\left(\chi^{2}\right)=15.57\right.$, $\mathrm{p}=0.001)$. The time to complete TMT was particularly long in the $3-6$ years group. Thus, the results show that the level of education highly affects the score on the TMT.

Multiple comparisons by Tests post hoc in the SPSS show that there were significant differences in the completion time of the Trail-A, between the $3-6$ and 7 - 10 years of educational groups $(\mathrm{p}=0.000)$; and between the $3-6$ and $\geq 11$-years of educational groups $(\mathrm{p}=0.000)$, but not between $7-10$ and $\geq 11$-years of educational groups $(\mathrm{p}=0.39)$.

For both versions of Trail-B (Moroccan/English), significant differences were found between the 3 - 6 and 7 - 10 years of educational groups $(p=0.000)$, and between the $3-6$ and $\geq 11$-years of educational groups ( $p=0.000$ ), whereas no significant differences were observed between 7 - 10 and $\geq 11$-years of educational groups ( $\mathrm{p}=0.28$ in Moroccan TMT-B and $\mathrm{p}=1.000$ in English TMT-B).

\subsection{Normative Data for TMT Scores}

On the basis of the analysis of the effect of demographic variables, it was decided to stratify the norms of Trail-A and both versions of Trail B by age and education. The scores were divided into 4 age groups and 3 educational levels. The performance scores of the Trail A, Moroccan Trail B, English Trail B, Moroccan Trail B-A, English Trail B-A, stratified by age and education were shown in the forms of a mean, and standard deviation (see Table 1 ).

\section{Discussion}

\subsection{Gender Effect on the TMT}

The analysis of the effect of gender confirmed that there is no significant impact on Trail A, Moroccan Trail B and English Trail B performance, a finding which is consistent with other studies [14] [30] while studies, found that females have longer time scores than males in TMT-A [31]. In this respect [15], found that gender has a significant influence on TMT scores.

\subsection{Aging Effect on the TMT}

The time of the completion of the TMT was markedly increased in the $60-69$ years and $\geq 70$ year's groups in comparison with younger adults (18 - 39 years, 40 - 59 years). The findings and statistical analyses show that increasing age is highly associated with low performance in the 3 trails. These results are consistent with those presented in previous studies [14] [15] [30] [32] [33].

\subsection{Educational Effect on the TMT}

Our data suggest that the educational effect on TMT scores becomes apparent 
Table 1. Normative data for the TMT in Moroccan subjects.

\begin{tabular}{|c|c|c|c|c|c|c|}
\hline $\begin{array}{l}\text { Age group } \\
\text { (years) }\end{array}$ & $\begin{array}{c}\text { Years of } \\
\text { education }\end{array}$ & $\begin{array}{c}\text { TMT-A } \\
\text { time (s) } \\
\text { Mean (SD) }\end{array}$ & $\begin{array}{c}\text { Moroccan Trail-B } \\
\text { time (s) } \\
\text { Mean (SD) }\end{array}$ & $\begin{array}{c}\text { Original Trail-B } \\
\text { time (s) } \\
\text { Mean (SD) }\end{array}$ & $\begin{array}{l}\text { Moroccan } \\
\text { Trail B-A time (s) } \\
\text { Mean (SD) }\end{array}$ & $\begin{array}{c}\text { Original Trail B-A } \\
\text { time (s) } \\
\text { Mean (SD) }\end{array}$ \\
\hline \multirow{9}{*}{$18-39$} & $3-6$ & 60.31 & 139.61 & 141.04 & & \\
\hline & & (14.93) & (44.49) & $(47.86)$ & 79.53 & 72.42 \\
\hline & & $(\mathrm{n}=32)$ & $(\mathrm{n}=32)$ & $(\mathrm{n}=21)$ & $(40.37)$ & (41.59) \\
\hline & $7-10$ & 44.09 (11.89) & 111.03 & 116.96 & & \\
\hline & & $(\mathrm{n}=32)$ & $(35.66)$ & $(34.82)$ & 66.22 & 72.27 \\
\hline & & & $(\mathrm{n}=31)$ & $(\mathrm{n}=29)$ & $(31.34)$ & $(32.85)$ \\
\hline & $\geq 11$ & 38.56 & 92 & $89.21(26.32)$ & & \\
\hline & & $(23.33)$ & $(28.89)$ & $(\mathrm{n}=32)$ & 52.83 & 50.33 \\
\hline & & $(\mathrm{n}=32)$ & $(\mathrm{n}=31)$ & & $(23.55)$ & $(21.25)$ \\
\hline \multirow{9}{*}{$40-59$} & $3-6$ & 66.031 & 170.96 & 147.94 & & \\
\hline & & $(22.93)$ & $(68.85)$ & $(43.29)$ & 106.12 & 82.17 \\
\hline & & $(\mathrm{n}=32)$ & $(\mathrm{n}=32)$ & $(\mathrm{n}=17)$ & $(62.31)$ & $(40.65)$ \\
\hline & $7-10$ & 57.78 & 128.2 & 124.12 & & \\
\hline & & $(29.32)$ & $(48.10)$ & $(64.30)$ & 69.2 & 75.84 \\
\hline & & $(\mathrm{n}=32)$ & $(\mathrm{n}=31)$ & $(\mathrm{n}=25)$ & $(33.26)$ & $(58.71$ \\
\hline & $\geq 11$ & 47.71 & 108 & 100.03 & & \\
\hline & & $(12.77)$ & $(24.91)$ & $(30.11)$ & 59.90 & 50.54 \\
\hline & & $(\mathrm{n}=32)$ & $(\mathrm{n}=32)$ & $(\mathrm{n}=32)$ & $(23.53)$ & (29.44) \\
\hline \multirow{9}{*}{$60-69$} & $3-6$ & 112.16 & 227.69 & 189 & 139.47 & 110.42 \\
\hline & & $(82.56)$ & 76.32 & (61.13) & $(63.13)$ & (41.40) \\
\hline & & $(\mathrm{n}=31)$ & $(\mathrm{n}=31)$ & $(\mathrm{n}=9)$ & & \\
\hline & $7-10$ & 80.64 & 154.59 & 139.95 & & \\
\hline & & $(62.72)$ & $(54.01)$ & $(2.12)$ & 86.36 & 70.57 \\
\hline & & $(\mathrm{n}=28)$ & $(\mathrm{n}=22)$ & $(\mathrm{n}=21)$ & $(56.74)$ & (39.06) \\
\hline & $\geq 11$ & 65.84 & 156.96 & 153.92 & & \\
\hline & & $(23.94)$ & 61.89 & $(56.87)$ & 93.19 & 89.07 \\
\hline & & $(\mathrm{n}=32)$ & $(\mathrm{n}=27)$ & $(\mathrm{n}=28)$ & $(48.38)$ & (41.01) \\
\hline \multirow{9}{*}{$\geq 70$} & $3-6$ & 120 & 248.26 & 245.72 & 153.42 & 149.09 \\
\hline & & (84.10) & (73.59) & $(80.30)$ & $(71.74)$ & $(78.22)$ \\
\hline & & $(\mathrm{n}=25)$ & $(\mathrm{n}=19)$ & $(\mathrm{n}=11)$ & & \\
\hline & $7-10$ & 79.33 & 217.33 & 214.31 & & \\
\hline & & $(30.86)$ & $(78.74)$ & (86.18) & 145.4 & 139.26 \\
\hline & & $(\mathrm{n}=21)$ & $(\mathrm{n}=18)$ & $(\mathrm{n}=19)$ & (79.05) & (75.07) \\
\hline & $\geq 11$ & 72.78 & 184.76 & 176.94 & & \\
\hline & & $(33.72)$ & $(100.05)$ & (101.48) & 107.23 & 103.4 \\
\hline & & $(\mathrm{n}=19)$ & $(\mathrm{n}=13)$ & $(\mathrm{n}=18)$ & (75.57) & (81.88) \\
\hline
\end{tabular}

and statistically significant with the population including poorly educated subjects (3 - 6 years), is highly consistent with previous reports, [14] [15] [32] [33]. 


\subsection{A Comparison of Present Study Results and Other Published Studies}

Our study is one of the first conducted in the Greater Maghreb countries on the issue of examining TMT scores in a sample of subjects. As expected we have found different TMT scores between the present study and those reported by other published studies. Incomparability of samples and administration differences were the most likely factors accounting for differences when a cross- cultural comparison of test results is [34] [35].

The demographic characteristics are not similar to the other two Arabic TMT studies [10] [11]. In Stanczak et al. [10], a sample of 77 Arabic-English bilingual Normal Sudanese, most of whom were functioning in a professional capacity. Their ages ranged from 17 to 31 years. In Abdul Razzak [11], she studied 152 Arabic-English bilingual medical students, from three Arabian Gulf states (between the 1st and 4th years, with more than 12 years of education). Their ages ranged from 18 to 23 years.

The present study involves 348 healthy volunteers from undergraduate university students and staff; social organizations; and a pool of people employed in, or retired from, governmental and/or private institutions. Ages ranged from 18 to 85 years $(M=51.57 \pm 18.32)$. The education level varied from 3 to 26 years $(\mathrm{M}=9.21 \pm 4)$. There were 229 dominant Arabic French bilingual subjects among the initial group of 348 subjects. These 229 completed both versions of Trail B (with Latin and Arabic letters).

Let us compare Moroccan Arabic TMT-B completion time to Sudanese and Arabian Gulf states samples. Both groups have comparable age (18 and 39 years) and education ( $>12$ years). We found the Arabian Gulf States sample has the best time with/by $71.83 \pm 17.42$ seconds, corresponding to the mean natural logarithm of 4.24. The Moroccan sample has $92 \pm 20.32$ seconds, corresponding to the mean natural logarithm of 4.52. In last place the Sudanese sample has a mean natural logarithm of 4.80 .

Normative data from the three different Arabian Studies are not equivalent. The present study does not provide a rationale for finding differences in TMT performance. Arab countries share the classical form of the written Arabic language but language situation and ethnocultural characteristics are incomparable. Abdul Razzak [11], explained that socioeconomic status, nutrition, education, and health care are better in the Arabian Gulf states than other Arab countries. Accordingly, it seems unlikely that Arabic TMT norms are uniform for all Arabic countries.

In the English TMT with Latin letters and Arabic numbers, we found the Arabian Gulf sample to be the highest with $25.7 \pm 7.67$ seconds in part A; and 58.777 \pm 12.12 seconds in part B. In second place, the Moroccan sample is $38.56 \pm 8.78$ seconds in part $\mathrm{A}$; and $=89.21 \pm 19.19$ seconds in part $\mathrm{B}$.

This finding is potentially confounded by sample differences in terms of age and education. The Arabian Gulf sample was younger (18 to 23 years) than the 
Moroccan sample (aged 18 to 39 years/M = 27.46). According to Mitrushina et al. [36], age is the most important demographic variable in TMT performance. Abdul Razzak's sample included only medical students. The Moroccan sample is composed of undergraduate university students from different departments, university staff and some social organizations. According to Bezdicek et al. [37], educational effects may go far beyond years of education and can possibly be a driving force in sociocultural differences in test performance. We accept Fernandez \& Marcopulus hypothesis [35] that in TMT studies the most likely source of variability in international normative values is method bias. Incomparability of samples and administration differences may be the main reason the norms are not comparable, and do not reflect real differences in the underlying construct [35].

In the present study 229 dominant bilingual subjects completed both versions of Trail B (Moroccan Arabic and English). There was no difference in observed performance in TMT completion times. In contrast, Abdul Razzak [11] found that the scores on the English TMT (both parts) is significantly better than the Arabic TMT among the participants who use Arabic as their native language.

\section{Conclusion}

In this study our goal was to adapt TMT-B to Moroccan subjects. We examined the effect of demographic factors on the performance of Trail A, Moroccan Trail $B$ and English Trail B. Our findings should be considered preliminary until more matched samples can be examined. Moroccan neuropsychologists (clinicians or researchers) can use both versions of Trail B in order to determine the degree to which the TMT scores reflect a deterioration in the performance of different ages and levels of instruction.

\section{Acknowledgements}

We appreciate participants for their cooperation to advance scientific research in our country.

\section{References}

[1] Siegert, R.J. and Cavana, C.M. (1997) Norms for Older New Zealanders on the Trail-Making Test. New Zealand Journal of Psychology, 26, 25-31.

[2] Strauss, E., Sherman, E.M.S. and Spreen, O. (2006) A Compendium of Neuropsychological Tests: Administration, Norms, and Commentary. 3rd Edition, Oxford University Press, New York.

[3] Rabin, L.A., Barr, W.B. and Burton, L.A. (2005) Assessment Practices of Clinical Neuropsychologists in the United States and Canada: A Survey of INS, NAN, and APA Division 40 Members. Archives of Clinical Neuropsychology: The Official Journal of the National Academy of Neuropsychologists, 20, 33-65. https://doi.org/10.1016/j.acn.2004.02.005

[4] Salthouse, T.A. (2011) What Cognitive Abilities Are Involved in Trail-Making Performance? Intelligence, 39, 222-232. https://doi.org/10.1016/j.intell.2011.03.001

[5] Sánchez-Cubillo, I., Periáñez, J.A., Adrover-Roig, D., Rodríguez-Sánchez, J.M., 
Ríos-Lago, M., Tirapu, J. and Barceló, F. (2009) Construct Validity of the Trail Making Test: Role of Task-Switching, Working Memory, Inhibition/Interference Control, and Visuomotor Abilities. Journal of the International Neuropsychological Society, 15, 438-450. https://doi.org/10.1017/S1355617709090626

[6] Barncord, S.W. and Wanlass, R.L. (2001) The Symbol Trail Making Test: Test Development and Utility as a Measure of Cognitive Impairment. Applied Neuropsychology, 8, 99-103. https://doi.org/10.1207/S15324826AN0802_4

[7] Killigore, W.D.S. (1999) A New Method for Assessing Subtle Cognitive Deficits: The Clock Trail-Making Test. [ABSTRACT]. Archives of Clinical Neuropsychology, 14, 92-93. https://doi.org/10.1093/arclin/14.1.92a

[8] D’Elia, L.F. and Satz, P. (1986) Color Trails 1 and 2. Psychological Assessment Resources, Odessa, FL.

[9] Fossum, B., Holmberg, H. and Reinvang, I. (1992) Spatial and Symbolic Factors in Performance on the Trail Making Test. Neuropsychology, 6, 71-75. https://doi.org/10.1037/0894-4105.6.1.71

[10] Stanczak, D.E., Stanczak, E.M. and Awadalla, A.W. (2001) Development and Initial Validation of an Arabic Version of the Expanded Trail Making Test: Implications for Cross-Cultural Assessment. Archives of Clinical Neuropsychology, 16, 141-149.

[11] RAbdul Razzak, R. (2013) A Preliminary Study on the Trail-Making Test in Arabic-English Bilingual Young Adults. Applied Neuropsychology: Adult, 20, 53-60. https://doi.org/10.1080/09084282.2012.670163

[12] Lu, L. and Bigler, E.D. (2002) Performance on Original and a Chinese Version of Trail Making Test Part B: A Normative Bilingual Sample. Applied Neuropsychology, 7, 243-246. https://doi.org/10.1207/S15324826AN0704_6

[13] Axelrod, B.N., Aharon-Peretz, J., Tomer, R. and Fisher, T. (2000) Creating Interpretation Guidelines for the Hebrew Trail Making Test. Applied Neuropsychology, 7, 186-188. https://doi.org/10.1207/S15324826AN0703_8

[14] Hashimoto, R., Meguro, K., Lee, E., Kasai, M., Ishii, H. and Yamaguchi, S. (2006) Effect of Age and Education on the Trail Making Test and Determination of Normative Data for Japanese Elderly People: The Tajiri Project. Psychiatry and Clinical Neurosciences, 60, 422 428. https://doi.org/10.1111/j.1440-1819.2006.01526.x

[15] Cangoz, B., Karakoc, E. and Selekler, K. (2009) Trail Making Test: Normative Data for Turkish Elderly Population by Age, Sex and Education. Journal of the Neurological Sciences, 283, 73-78. https://doi.org/10.1016/j.jns.2009.02.313

[16] Bhatia, T., Shriharsh, V., Adlakha, S., Bisht, V., Garg, K. and Deshpande, S.N. (2007) The Trail Making Test in India. Indian Journal of Psychiatry, 49, 113116. https://doi.org/10.4103/0019-5545.33258

[17] Jacobson, S.C., Blanchard, M., Connolly, C.C., Cannon, M. and Garavan, H. (2011) An fMRI Investigation of a Novel Analogue to the Trail-Making Test. Brain and Cognition, 77, 60-70. https://doi.org/10.1016/j.bandc.2011.06.001

[18] Shibuya-Tayoshi, S., Sumitani, S., Kikuchi, K., Tanaka, T., Tayoshi, S., Ueno, S.-I. and Ohmori, T. (2007) Activation of the Prefrontal Cortex during the Trail-Making Test Detected with Multichannel Near-Infrared Spectroscopy. Psychiatry and Clinical Neurosciences, 61, 616-621. https://doi.org/10.1111/j.1440-1819.2007.01727.x

[19] Nakahachi, T., Ishii, R., Iwase, M., Canuet, L., Takahashi, H., Kurimoto, R. and Takeda, M. (2010) Frontal Cortex Activation Associated with Speeded Processing of Visuospatial Working Memory Revealed by Multichannel Near-Infrared Spectroscopy during Advanced Trail Making Test Performance. Behavioural Brain Research, 215, 21-27. https://doi.org/10.1016/j.bbr.2010.06.016 
[20] Zakzanis, K.K., Mraz, R. and Graham, S.J. (2005) An fMRI Study of the Trail Making Test. Neuropsychologia, 43, 1878-1886.

[21] Albert, M.S., Moss, M.B., Tanzi, R. and Jones, K. (2001) Preclinical Prediction of AD Using Neuropsychological Tests. Journal of the International Neuropsychological Society, 7, 631-639. https://doi.org/10.1017/S1355617701755105

[22] Ashendorf, L., Jefferson, A.L., O’Connor, M.K., Chaisson, C., Green, R.C. and Stern, R.A. (2008) Trail Making Test Errors in Normal Aging, Mild Cognitive Impairment, and Dementia. Archives of Clinical Neuropsychology, 23, 129-137. https://doi.org/10.1016/j.acn.2007.11.005

[23] Lee, T., Cheung, C., Chan, C., Yip, J., Cheung, P. and Chan, C. (2000) Trail Making across Languages. Archives of Clinical Neuropsychology, 15, 702.

[24] Chan, A.S., Shum, D. and Cheung, R.W. (2003) Recent Development of Cognitive and Neuropsychological Assessment in Asian Countries. Psychological Assessment, 15, 257-267. https://doi.org/10.1037/1040-3590.15.3.257

[25] Boone, K.B., Victor, T.L., Wen, J., Razani, J. and Pontón, M. (2007) The Association between Neuropsychological Scores and Ethnicity, Language, and Acculturation Variables in a Large Patient Population. Archives of Clinical Neuropsychology: The Official Journal of the National Academy of Neuropsychologists, 22, 355-365. https://doi.org/10.1016/j.acn.2007.01.010

[26] Razani, J., Burciaga, J., Madore, M. and Wong, J. (2007) Effects of Acculturation on Tests of Attention and Information Processing in an Ethnically Diverse Group. Archives of Clinical Neuropsychology: the official journal of the National Academy of Neuropsychologists, 22, 333-341. https://doi.org/10.1016/j.acn.2007.01.008

[27] Ennaji, M. (2005) Multilingualism, Cultural Identity, and Education in Morocco. Springer, Edition Number 1.

[28] Battenburg, J. (1997) English versus French: Language Rivalry in Tunisia. World Englishes, 16, 281-290. https://doi.org/10.1111/1467-971X.00062

[29] El Alaoui, F.M., Benabdljlil, M., Boutazout, M., Mouji, F., Agoulmame, M., Rahmani, M., Berremdane, M., Ait Benhaddou, H., Ettahiri, L. and Chekili, T. (2003) Adaptation et validation du Mini-Mental State Examination (MMSE) en Arabe. [Adaptation and Validation of the Mini-Mental State Examination (MMSE) in Arabic.] Revue de Neurologie (Paris), 159, 146.

[30] Tombaugh, T.N. (2004) Trail Making Test A and B: Normative Data Stratified by Age and Education. Archives of Clinical Neuropsychology, 19, 203-214.

[31] Giovagnoli, A.R., Del Pesce, M., Mascheroni, S., Simoncelli, M., Laiacona, M. and Capitani, E. (1996) Trail Making Test: Normative Values from 287 Normal Adult Controls. Italian Journal of Neurological Sciences, 17, 305-309. https://doi.org/10.1007/BF01997792

[32] Hamdan, A.C. and Hamdan, E.M.L.R. (2009) Effects of Age and Education Level on the Trail Making Test in A healthy Brazilian Sample. Psychology \& Neuroscience, 2, 199-203. https://doi.org/10.3922/j.psns.2009.2.012

[33] Seo, E.H., Lee, D.Y., Kim, K.W., Lee, J.H., Jhoo, J.H., Youn, J.C., Woo, J.I., et al. (2006) A Normative Study of the Trail Making Test in Korean Elders. International Journal of Geriatric Psychiatry, 21, 844-852. https://doi.org/10.1002/gps.1570

[34] Van de Vijver, F. and Tanzer, N. (1997) Bias and Equivalence in Cross-Cultural Assessment: An Overview. European Review of Applied Psychology, 47, 263-279.

[35] Fernandez, A.L. and Marcopulus, B.A. (2008) A Comparison of Normative Data for the Trail Making Test from Several Countries: Equivalence of Norms and Consid- 
erations for Interpretation. Scandinavian Journal of Psychology, 49, 239-246. https://doi.org/10.1111/j.1467-9450.2008.00637.x

[36] Mitrushina, M.N., Boone, K.B. and D’Elia, L.F. (1999) Handbook of Normative Data for Neuro-Psychological Assessment. Oxford University Press, New York.

[37] Bezdicek, Moták, Schretlen, Preiss, Axelrod, Nikolai, Peña, Ojeda and Růžička (2016) Sociocultural and Language Differences on the Trail Making Test. Archives of Assessment Psychology, 6, 33-48. 